\title{
Long term outcome of percutaneous mitral balloon valvotomy in patients aged 70 and over
}

\author{
N Sutaria, A T Elder, T R D Shaw
}

\begin{abstract}
Objective-To assess the immediate haemodynamic improvement and long term symptomatic benefit of percutaneous mitral balloon valvotomy in patients aged over 70 years.

Design-Pre- and postprocedure haemodynamic data and follow up for 1 to 10 years by clinic visit or telephone contact.

Setting-Tertiary referral centre in Scotland.

Subjects-80 patients age 70 and over who had mitral balloon dilatation: 55 were considered unsuitable for surgical treatment because of frailty or associated disease. In an additional four patients mitral dilatation was not achieved.

Main outcome measures-Increase in valve area after balloon dilatation and survival, freedom from valve replacement, and symptom class at follow up.

Results-Mean (SD) valve area increased by $89 \%$ from $0.84(0.28)$ to $1.59(0.67) \mathrm{cm}^{2}$. There was a low rate of serious complications, with only two patients having long term major sequelae. Of 55 patients unsuitable for surgical treatment, $28(51 \%)$ were alive without valve replacement and with improvement by at least one symptom class at one year, and $14(25 \%)$ at five years. In the 25 patients considered suitable for surgical treatment, $16(64 \%)$ achieved this outcome at one year and nine $(36 \%)$ at five years.

Conclusions-Percutaneous mitral balloon valvotomy is a safe and useful palliative procedure in elderly patients who are unsuitable for surgery. Balloon dilatation should also be used for elderly patients whose valve appears suitable for improvement by commissurotomy, but echo score is an imperfect predictor of haemodynamic improvement.
\end{abstract}

(Heart 2000;83:433-438)

Keywords: mitral valve stenosis; balloon valvotomy; elderly patients

In 1984 Inoue et al developed the new option of balloon dilatation for the management of mitral stenosis. ${ }^{1}$ Balloon dilatation produces a commissurotomy similar to that obtained by surgery ${ }^{2}$ but is a percutaneous procedure, using only local anaesthesia. Several large series $^{3-5}$ have shown that balloon dilatation is effective in providing sustained haemodynamic and symptomatic improvement of patients with severe mitral stenosis, the degree of improvement depending principally on valve anatomy. ${ }^{4}$

In patients with pliable valves, randomised trials $^{6-11}$ have shown that mitral balloon valvotomy gives an excellent result equal to that obtained with open or closed surgical valvotomy and benefit is sustained during long term follow up. ${ }^{12}$ Less effective results are obtained in patients with significant degenerative change in the mitral leaflets or subvalvar apparatus. ${ }^{13-15}$ Valve replacement is therefore the optimal choice for patients who have marked mitral valve degenerative change. In Western countries patients now presenting with severe mitral stenosis are not infrequently of advanced age, as acute rheumatic fever has almost disappeared ${ }^{16}$ and these elderly patients often have more marked valvar and subvalvar degenerative change and would normally require valve replacement. They are frequently, however, high risk candidates for cardiac surgery. Such patients may be content with a moderate improvement in symptoms if this allows them to regain an independent although restricted lifestyle. For this type of patient, therefore, percutaneous balloon valvotomy might still represent a useful palliative treatment with lower procedural risk. As mitral balloon valvotomy carries some risk to the patient and has an economic cost it would be justified only if significant symptomatic improvement continued for a reasonable length of time. We report our experience of mitral balloon valvotomy in patients aged 70 years and over, who have been followed for one to 10 years.

\section{Methods}

PATIENTS

Of 300 patients who had a mitral balloon valvotomy between 1986 and 1996, 80 (27\%) were aged 70 years or over. The mean (SD) age of these 80 patients was 75.2 (4.2) years (range 70 to 87 ). There was a history of rheumatic fever or chorea in $33(41 \%)$. A previous surgical valvotomy had been carried out in $16(20 \%)$ at a mean of 25.3 (7.5) years earlier (range 12 to 40). Patients had been referred from hospitals throughout Scotland. All were born in the United Kingdom. In an additional four patients balloon valvotomy could not be completed, as described below.

In this age group the clinical status of the patients varied greatly. They ranged from the fit elderly to those who were moribund. Fifty five $(69 \%)$ of these 80 patients were judged unsuitable for cardiac surgery by a cardiac surgeon or referring cardiologist. The principal reason for unsuitability for surgical treatment was 
additional cardiac disease in five (severe left ventricular impairment and/or ungraftable coronary disease), pulmonary disease in 12, and marked frailty in eight. Thirty patients had medical problems which singly or in combination had resulted in the patient being considered unsuitable for surgery. The medical problems were renal impairment, chronic neurological disability, coexisting cancer, severe arthritis, severe obesity, diabetes, pulmonary or cardiac disease, and moderate frailty. The mean number of additional medical problems in this group was 3.0 (range 1 to 7 ). Twenty five of the 80 patients had been considered as acceptable for surgery but on echocardiography had a mitral valve judged appropriate for treatment by balloon commissurotomy. The characteristics of the patients in these two groups are given in table 1. The Parsonnet score, a prediction of mortality in the perioperative period, was calculated for each patient. ${ }^{17}$

ECHOCARDIOGRAPHY

Transthoracic cross sectional echocardiography and Doppler/colour imaging were carried out before balloon valvotomy using standard techniques. Degenerative changes at the mitral valve were scored using the echo score developed at the Massachusetts General Hospital. ${ }^{14}{ }^{15}$ Echo scoring was by consensus of two observers and was done prospectively in 59 patients and retrospectively from video recordings in the first 21 patients. The latter 53 patients $(66 \%)$ also had a transoesophageal echo (TOE) study ${ }^{21}$ immediately before the planned procedure. In $17 \%$ of these patients left atrial thrombus was detected. The thrombus was within the auricular appendage in five and was a smooth laminar wall thrombus in two. These seven patients proceeded to same day mitral balloon valvotomy. In two patients, thrombus protruding into the left cavity was found and both had a further three month period of intensified anticoagulation before undergoing balloon valvotomy. In one of these two patients the thrombus had disappeared at

Table 1 Characteristics of 80 patients aged 70 years and over undergoing mitral balloon valvotomy and judged as unsuitable or suitable for cardiac surgery

\begin{tabular}{lll}
\hline & Unsuitable for surgery & Suitable for surgery \\
\hline Patients (n) & 55 & 25 \\
Female/male & $47 / 8(86 / 14)$ & $22 / 3(88 / 12)$ \\
Age (years) (mean (SD)) & $75.9(4.4)$ & $73.6(3.0)$ \\
Sinus rhythm & $5(9)$ & $4(16)$ \\
Mitral reflux & $27(49)$ & $10(40)$ \\
Aortic valve disease & $16(29)$ & $5(20)$ \\
LV impairment & $12(22)$ & $3(12)$ \\
Coronary artery disease & $29(53)$ & $5(20)$ \\
RV systolic pressure (mm Hg) (mean (SD)) & $62(24)$ & $47(15)$ \\
Range & $(21$ to 153$)$ & $(26$ to 90$)$ \\
NYHA symptom class & $0(0)$ & $0(0)$ \\
I & $1(2)$ & $4(16)$ \\
II & $26(47)$ & $14(56)$ \\
III & $28(51)$ & $7(28)$ \\
IV & & \\
Mitral valve calcification on fluoroscopy & $14(25)$ & $12(48)$ \\
None & $14(25)$ & $6(24)$ \\
Mild & $7(13)$ & $5(20)$ \\
Moderate & $20(36)$ & $2(8)$ \\
Severe & $8.3(3.2)$ & $7.4(2.7)$ \\
Echo score (mean (SD)) & $27.3(8.7)$ & $19.4(6.0)$ \\
Parsonnet score (mean (SD)) & 10 to 45 & 13 to 36 \\
$\quad$ Range & & \\
\hline
\end{tabular}

Values are $\mathrm{n}(\%)$ unless stated.

LV, left ventricular; NYHA, New York Heart Association; RV, right ventricular. repeat TOE, and in the other it had regressed and appeared organised. In one additional patient thrombus was situated at the interatrial septum; it persisted after intensive anticoagulation and she was referred for surgery. All of the patients found to have left atrial thrombus had been on warfarin treatment; nine of the 10 were in atrial fibrillation.

\section{MITRAL BALLOON VALVOTOMY}

Following local anaesthesia and cannulation of the right femoral artery and vein, all patients had right and left heart pressure recording and oxygen saturation measurement before and after balloon dilatation. Transmitral pressure gradient was measured by planimetry. Valve area was calculated by the Gorlin formula. ${ }^{18}$ Cardiac output was measured using assumed oxygen uptake. ${ }^{19}$ Coronary angiography was performed in all patients.

In the latter 64 patients, mitral dilatation was carried out using the equipment and technique described by Inoue. ${ }^{20}$ In the initial 16 patients, treated before the Inoue balloon was available in Europe, single or double cylindrical balloons were used. We found these two techniques to have the same haemodynamic outcome ${ }^{21}$ but there was a shorter procedure time and fewer complications with the Inoue technique. The mean (SD) effective balloon dilatation area ${ }^{22}$ was $3.5(0.52) \mathrm{cm}^{2} / \mathrm{m}^{2}$. All procedures were by one operator (TRDS).

In an additional four patients aged over 70, completed balloon dilatation at the mitral valve was not achieved. In three of the first 16 patients the cylindrical balloons then used could not be made to cross either the atrial septum or the mitral orifice. In one patient hemiplegia developed before Inoue balloon dilatation was complete.

FOLLOW UP

Symptom status (New York Heart Association (NYHA) symptom class) after valvotomy was established by clinic visit or telephone contact. Details of valve replacement and deaths were obtained from general practitioners and referring physicians and Health Board mortality records. Follow up was from one to 10 years and was $100 \%$ complete.

\section{STATISTICAL ANALYSIS}

Results are expressed as mean (SD) unless otherwise stated. Survival curves were made by the Kaplan-Meier method. Comparison of pre- and postdilatation data was by Student's paired $t$ test. Stepwise multiple linear regression analysis was used to assess the importance of sex, age, rhythm, mitral reflux, Parsonnet score, previous valvotomy, effective balloon area/body surface area, balloon type, commissure calcification, and echo score as predictors of haemodynamic outcome. A probability (p) value of less than 0.05 was considered to be statistically significant.

\section{Results}

Percutaneous mitral balloon dilatation was well tolerated, even in the critically ill patients, and no patient died or developed a sustained major 
Table 2 Haemodynamic findings before and after mitral balloon valvotomy

\begin{tabular}{|c|c|c|c|c|c|c|c|c|}
\hline \multirow[b]{2}{*}{ Patients } & \multicolumn{2}{|c|}{$\begin{array}{l}\text { Transmitral gradient } \\
(\mathrm{mm} \mathrm{Hg})\end{array}$} & \multicolumn{2}{|c|}{ Cardiac output (l/mm) } & \multicolumn{2}{|c|}{ Valve area $\left(\mathrm{cm}^{2}\right)$} & \multirow{2}{*}{$\begin{array}{l}\text { Final valve area } \\
>1.5 \mathrm{~cm}^{2}\end{array}$} & \multirow{2}{*}{$\begin{array}{l}\text { Final valve area } \\
1.2 \mathrm{~cm}^{2}\end{array}$} \\
\hline & Before & After & Before & After & Before & After & & \\
\hline All patients $(\mathrm{n}=80)$ & $11.6(2.9)$ & $5.6(2.6)$ & $3.26(0.87)$ & $4.15(1.81)$ & $0.84(0.28)$ & $1.59(0.67)$ & $37 / 80(46 \%)$ & $57 / 80(71 \%)$ \\
\hline Unsuitable for surgery $(n=55)$ & $11.9(4.4)$ & $5.7(2.7)$ & $3.26(0.96)$ & $4.27(2.11)$ & $0.81(0.31)$ & $1.58(0.74)$ & $\begin{array}{l}22 / 55(40 \%) \\
\mathrm{ES}>8: 7 / 25(28 \%) \\
\mathrm{ES} \leq 8: 15 / 30(50 \%)\end{array}$ & $\begin{array}{l}37 / 55(67 \%) \\
\text { ES > 8: } 11 / 25(44 \%) \\
\text { ES } \leq 8: 26 / 30(87 \%)\end{array}$ \\
\hline Suitable for surgery $(n=25)$ & $11.0(5.5)$ & $5.3(3.2)$ & $3.27(0.66)$ & $3.88(0.83)$ & $0.89(0.21)$ & $1.61(0.49)$ & $\begin{array}{l}15 / 26(60 \%) \\
\text { ES }>8: 3 / 6(50 \%) \\
\text { ES } \leq 8: 12 / 19(63 \%)\end{array}$ & $\begin{array}{l}20 / 25(80 \%) \\
\text { ES }>8: 4 / 6(67 \%) \\
\text { ES } \leq 8: 16 / 19(84 \%)\end{array}$ \\
\hline
\end{tabular}

Values are mean (SD). All changes were statistically significant.

ES, echo score.

arrhythmia, pulmonary oedema, or shock during the procedure or required a vascular repair procedure.

HAEMODYNAMIC CHANGE

The haemodynamic findings before and after balloon dilatation are given in table 2 . Overall the mean transmitral gradient was reduced by $52 \%$, cardiac output rose by $27 \%$, and valve area increased by $89 \%$. Postdilatation valve areas greater than $1.50 \mathrm{~cm}^{2}$ and $1.20 \mathrm{~cm}^{2}$ were achieved in $40 \%$ and $67 \%$ of those unsuitable for surgery and in $57 \%$ and $80 \%$ of those suitable for surgery, respectively. In both groups patients with an echo score $\leq 8$ were more likely to achieve these targets. The increase in valve area showed a significant but weak correlation with echo score $(r=0.22, \mathrm{p}<0.05)$ (fig 1). However, on multiple linear regression analysis only echo score (odds ratio $0.81,95 \%$ confidence interval (CI) 0.69 to 0.96 ) and female sex (odds ratio $0.19,95 \%$ CI 0.04 to 87) were independent predictors of failure to achieve a valve area greater than $1.50 \mathrm{~cm}^{2}$ (both $\mathrm{p}<0.05)$. Haemodynamic change was similar in the four comorbidity subgroups.

COMPLICATIONS

Sixteen patients $(20 \%)$ developed an increase in mitral reflux after dilatation. However, immediately after final dilatation reflux became mild in 11 , moderate in five, and severe in none. No patient required emergency valve replacement. In 14 patients (18\%), oxygen saturation measurement detected a left to right shunt from atrial septal puncture of more than 1.2 to 1 (mean $1.50(0.39)$, range 1.2 to 2.7 ). One patient, treated by the double cylindrical balloon method, developed marked atrial shunting (2.7:1) and later required surgical repair of the atrial septum at the time of valve

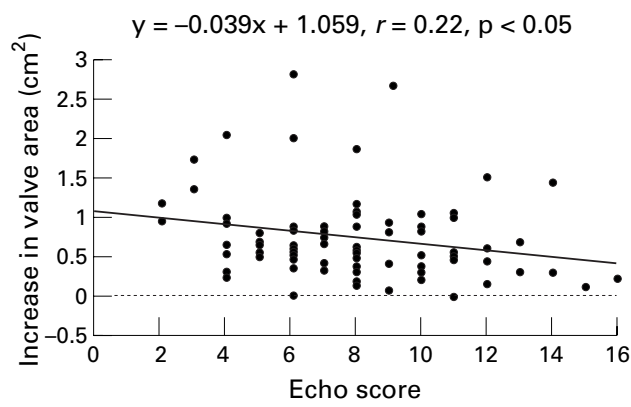

Figure 1 Correlation between echo score and increase in valve area after mitral balloon dilatation. replacement. Three of the 80 patients showed evidence of systemic embolism. One patient who did not have TOE before balloon valvotomy had a coronary embolus with subsequent mild left ventricular impairment. One patient in whom TOE showed no left atrial thrombus had transient foot ischaemia. A patient with laminar thrombus at TOE had transient diplopia. An additional patient, in whom mitral balloon dilatation was not completed, had protuberant left atrial thrombus, which was erroneously thought to have become organised and adherent at repeat TOE after intensive anticoagulant treatment. This patient developed a severe hemiplegia, giving a total embolism rate of $5 \%$. A small $(1 \mathrm{~cm})$ asymptomatic haemopericardium was detected on postvalvotomy echocardiography in one patient. Thus overall, only two of the patients developed a severe persistent complication.

\section{SYMPTOM OUTCOME}

The Kaplan-Meier survival curves for patients suitable and unsuitable for surgery are shown in fig 2 and are compared to those of age and sex matched cohorts. In such elderly patients one test of benefit is whether the patient is alive, has not undergone or been referred for valve replacement, and remains improved by at least one NYHA symptom class. Figure 2 also shows the survival curves of those achieving this criterion. Of the 55 patients judged unsuitable for surgery this criterion was achieved at one year by just over half the patients $(n=28$, $51 \%)$, at three years by $20(37 \%)$, at five years by $14(25 \%)$, and at seven years by $10(18 \%)$. In these 55 patients initially judged unacceptable for surgery, five who did not improve with balloon valvotomy and remained very severely disabled were subsequently reconsidered by the cardiac surgeons and accepted for operation. However, operative mortality was $40 \%$ and only one patient had an improvement in symptoms, confirming the poor surgical outlook for this type of patient. In the 25 cases considered suitable for surgery, the criterion was reached at one year by $16(64 \%)$ and at three, five, and seven years by $11(45 \%)$, nine $(36 \%)$, and nine $(36 \%)$, respectively. After balloon valvotomy, six of these 25 patients had valve replacement: operative mortality was $17 \%$ and all the survivors obtained symptomatic benefit.

Symptom class before balloon valvotomy and at 1-2 months, 1, 3, 5, and 7 years afterwards are given in table 3. 

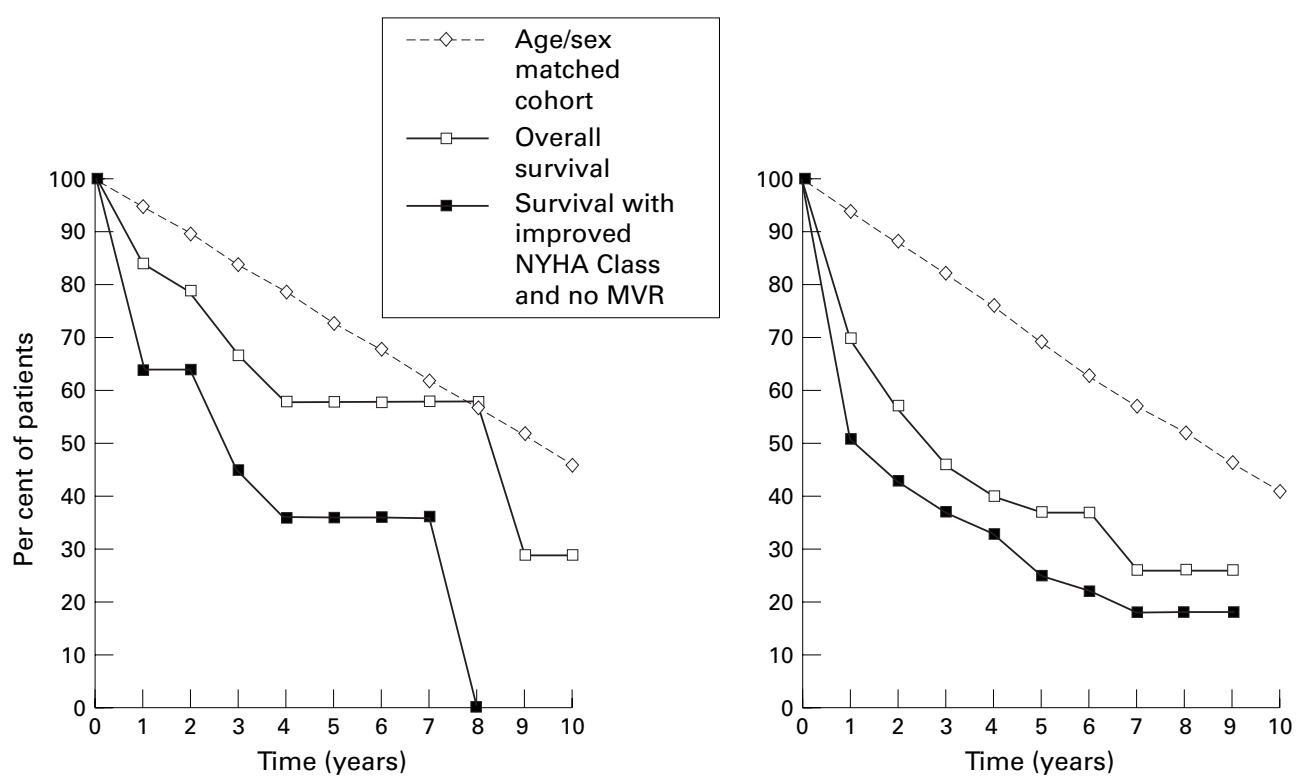

Figure 2 Survival and clinical status following mitral balloon valvotomy in patients who were suitable (left panel) or unsuitable (right panel) for surgery, and age and sex matched cohorts.

In both groups there was a progressive loss of symptomatic benefit in survivors but improvement was maintained for several years.

\section{Discussion}

Percutaneous mitral balloon valvotomy was well tolerated in this group of elderly, often frail and sometimes very ill patients, and produced haemodynamic improvement. The low rate of complications was similar to that found in younger patients, ${ }^{3-11}$ although the final mitral valve area was smaller than in young patients with pliable valves. The procedure would be justified, however, only if it appeared to offer a better outcome than continued medical treatment or surgical treatment.

In $94 \%$ of the patients there was very severe symptomatic limitation (NYHA class III and IV) despite intensive medical treatment. In these patients medical treatment had been maintained longer than would be usual for younger, more active patients. Continued medical treatment was not an effective option

Table 3 Symptom status of patients suitable and unsuitable for surgery before mitral balloon valvotomy $(M B V)$ and at various times afterwards

\begin{tabular}{|c|c|c|c|c|c|c|}
\hline \multirow[b]{2}{*}{$\begin{array}{l}\text { NYHA symptom } \\
\text { class }\end{array}$} & \multirow[b]{2}{*}{ Before $M B V$} & \multicolumn{5}{|l|}{ After $M B V$} \\
\hline & & 1-2 months & 1 year & 3 years & 5 years & 7 years \\
\hline \multicolumn{7}{|c|}{ Patients suitable for surgery } \\
\hline I & 0 & 20 & 28 & 19 & 22 & 20 \\
\hline II & 16 & 52 & 28 & 19 & 0 & 0 \\
\hline III & 56 & 24 & 16 & 12 & 11 & 20 \\
\hline IV & 4 & 4 & 0 & 0 & 0 & 0 \\
\hline MVR & - & 0 & 12 & 19 & 22 & 20 \\
\hline Died & - & 0 & 16 & 31 & 45 & 40 \\
\hline (n) & $(25)$ & $(25)$ & (25) & (16) & (9) & (5) \\
\hline \multicolumn{7}{|c|}{ Patients unsuitable for surgery } \\
\hline I & 0 & 15 & 15 & 9 & 3 & 0 \\
\hline II & 2 & 49 & 33 & 21 & 16 & 10 \\
\hline III & 49 & 25 & 9 & 14 & 16 & 16 \\
\hline IV & 49 & 11 & 7 & 2 & 0 & 0 \\
\hline MVR & - & 0 & 5 & 0 & 0 & 0 \\
\hline $\begin{array}{l}\text { Died } \\
(\mathrm{n})\end{array}$ & $\begin{array}{c}- \\
(55)\end{array}$ & $\begin{array}{c}0 \\
(55)\end{array}$ & $\begin{array}{l}31 \\
(55)\end{array}$ & $\begin{array}{l}54 \\
(43)\end{array}$ & $\begin{array}{l}65 \\
(31)\end{array}$ & $\begin{array}{l}74 \\
(19)\end{array}$ \\
\hline
\end{tabular}

Values are percentage or (number).

MVR, mitral valve replacement; NYHA, New York Heart Association. for these patients: some were bed bound and for many others their cardiac symptoms threatened their independent lifestyle.

Mitral valve replacement in elderly people has a much higher mortality and poorer outcome than in younger patients. Nicolaou and Kinsley ${ }^{24}$ had a $23 \% 30$ day mortality in 35 patients aged over 70 undergoing mitral valve replacement. Postoperative complications occurred in $57 \%$ and mean hospital stay was 16 days. Nair et al found a $27 \%$ perioperative mortality in 26 patients aged over 70, compared with $12 \%$ in younger patients ${ }^{25}$ : at five years after mitral valve replacement $54 \%$ of their elderly patients had died. Edmunds et al had a 90 day mortality of $29 \%$ in octogenarians undergoing valve replacement. ${ }^{26}$ In a large series of 504 patients aged over 70 who had mitral valve replacement (35\% with concomitant coronary bypass grafts and $38 \%$ with an additional valve replacement) between 1976 and 1996, Grossi et al reported a hospital mortality of $17 \%$; for mitral valve replacement alone mortality was $13 \% .{ }^{27}$ Even after surviving mitral valve replacement, patients aged over 70 have about $50 \%$ mortality at four to five years after operation ${ }^{26}$ and the majority remain symptomatic.

Fifty five of our 80 elderly patients were considered to be unsuitable for surgical treatment because of their frailty or additional medical problems. Their Parsonnet score predicted a perioperative mortality of $27 \%$. Many of these 55 patients had degenerative changes at the mitral valve and a high mean echo score of 8.3 - mitral balloon dilatation had been undertaken even when the valve anatomy was unattractive for commissurotomy. In these circumstances balloon valvotomy might still be a useful palliative procedure for the inoperable patient, if even a moderate improvement in symptoms was achieved. In this group, 51\% were alive and improved by at least one symptom class at one year after the procedure. This 
benefit decreased with time but lasted a reasonable period, given the age and medical condition of the patients. Iung et al achieved a mitral valve area greater than $1.5 \mathrm{~cm}^{2}$ in $66 \%$ of their 75 patients aged over 70 undergoing mitral balloon valvotomy; four year survival was $59 \%{ }^{23}$

Our 25 elderly patients who were suitable for surgery underwent balloon valvotomy because their valve anatomy appeared favourable for commissurotomy or because of their reluctance to undergo operation: only six of the 25 patients had an echo score greater than 8 . At one year after balloon valvotomy $64 \%$ remained improved by at least one NYHA symptom class, without valve replacement. Six of the 25 patients subsequently had valve replacement, with a perioperative mortality of $17 \%$. These patients, whose mean age was 74 , therefore fared moderately well after balloon valvotomy, but significant symptomatic improvement was not achieved in one third at one year. Ideally echocardiography would select accurately those patients who would obtain substantial haemodynamic and symptomatic improvement from balloon dilatation. We found, as have others, that the echo score was an imperfect predictor of increase in valve area. Commissural calcification, which is not included in the echo score, is not uncommon in the elderly and also influences outcome. ${ }^{28} 29$ There is a need to improve case selection so that in those patients suitable for surgery one could identify those who would achieve adequate symptomatic improvement by balloon dilatation, while taking account of the more restricted desired lifestyle of the elderly and their higher surgical risk.

Left atrial thrombus was found in 10 of the 54 patients who had TOE immediately before planned balloon valvotomy despite the fact that all were on warfarin treatment. This was a higher incidence than found in younger patients. Mitral balloon dilatation was safely undertaken in those with appendicular or laminar thrombus but any thrombus protruding into the left atrial cavity should be a contraindication to balloon valvotomy.

This study included only patients referred for consideration for mitral balloon valvotomy and does not reflect the characteristics of all patients aged over 70 who have mitral stenosis. Relatively fit patients with markedly degenerate mitral valves may have been referred by their cardiologist direct for cardiac surgery. Other frail patients with severe mitral stenosis who were sufficiently controlled on medical treatment may not have been referred for balloon valvotomy.

The report of the Royal College of Physicians of London, Cardiological intervention in elderly patients, ${ }^{30}$ stated that "the goals of medical intervention are improvement in function and postponement of disability, so extending the period of active independent life." Percutaneous balloon valvotomy can help to achieve this for many elderly patients with mitral stenosis. In severely symptomatic patients unable to have cardiac surgery, percutaneous balloon valvotomy is virtually always worth attempting if there is any commissural fusion. In elderly patients who are acceptable for operation, the echo score gives an approximate prediction of balloon valvotomy outcome: transoesophageal assessment of commissure fusion and morphology may help to improve assessment. $^{31}$

1 Inoue K, Owaki T, Nakamura T, et al. Clinical application of transvenous mitral commissurotomy by a new balloon catheter. F Thoracic Cardiovasc Surg 1984;87:394-402.

2 Kaplan JD, Isner JM, Karas RH, et al. In vitro analysis of mechanisms of balloon valvuloplasty of stenotic mitral mechanisms of balloon valvuloplasty
valves. Am f Cardiol 1987;59:318-23.

3 Dean LS, Mickel M, Bonan R, et al, for the Balloon Valvuloplasty Registry participants. Long-term follow up of patients undergoing percutaneous balloon mitral commissurotomy: a report from the National Heart, Lung and Blood Institute Balloon Valvuloplasty Registry. Circulation 1994;90:1-65.

4 Palacios IF, Tuzcu ME, Weyman AE, et al. Clinical follow up of patients undergoing percutaneous mitral balloon valvotomy. Circulation 1995;91:671-6.

5 Chen C, Chen TO. Percutaneous balloon mitral valvuloplasty using Inoue technique: a multicenter study of 4832 patients in China. Am Heart f 1995;129:1197-204.

6 Patel JJ, Sharma D, Mitha AS, et al. Balloon valvuloplasty versus closed commissurotomy for pliable mitral stenosis: a prospective hemodynamic study. $f \mathrm{Am}$ Coll Cardiol 1991;18:1318-22.

7 Turi ZG, Reyes VP, Raju BS, et al. Percutaneous balloon versus surgical closed commissurotomy for mitral stenosis: a prospective, randomised trial. Circulation 1991;83:117985 .

8 Shrivastava S, Mathur A, Dev V, et al. Comparison of immediate hemodynamic response of closed mitral commissurotomy, single balloon and double balloon mitral valvuloplasty in rheumatic mitral stenosis. $\mathcal{F}$ Thorac Cardiovasc Surg 1992;104:1264-7.

9 Arora R, Nair M, Kalra GS, et al. Immediate and long term results of balloon and surgical closed valvotomy: a
randomised comparative trial. Am Heart f 1993;125:10914.

10 Reyes VP, Raju BS, Wynne J, et al. Percutaneous balloon valvuloplasty compared with open surgical commisvalvuloplasty compared with open s.
surotomy. $N$ Engl f Med 1994;331:961-7.

11 Farhat MB, Ayani M, Maatouk F, et al. Percutaneous balloon versus surgical closed and open mitral commissurotomy: seven-year follow up results of a commissurotomy: seven-year follow up resu

12 Chen CR, Cheng TO, Chen JY, et al. Long-term results of percutaneous balloon mitral valvuloplasty for mitral stenosis: a follow up study to 11 years in 202 patients. Cathet Cardiovasc Diagn 1998;43:132-9.

13 Iung B, Cormier B, Ducimetiére P, et al. Functional results 5 years after successful percutaneous mitral commissurotomy in a series of 528 patients and analysis of predictive factors. I Am Coll Cardiol 1996;27:407-14.

14 Wilkins GT, Weyman AE, Abascal VM, et al. Percutaneous balloon dilatation of the mitral valve: an analysis of echocardiographic variables related to outcome and the mechanism of dilatation. Br Heart $\mathcal{F}$ 1988;60:299-308.

15 Abascal VM, Wilkins GT, O'Shea, et al. Prediction of successful outcome in 130 patients undergoing percutanesuccessful outcome in 130 patients undergoing percutane-
ous balloon mitral valvotomy. Circulation 1990;82:448-56.

16 Carroll JD, Feldman T. Percutaneous mitral balloon Carroll JD, Feldman T. Percutaneous mitral balloon
valvotomy and the new demographics of mitral stenosis. valvotomy and the new dem
fAMA 1993;270:1731-6.

17 Parsonnet V, Dean D, Bernstein AD. A method of uniform stratification of risk for evaluating the results of surgery in acquired adult heart disease. Circulation 1989;79(suppl I):3-12

18 Cohen MV, Gorlin R. Modified orifice equation for the calculation of mitral valve area. Am Heart f 1972;84:839.

19 Hall RJC, Julian DG. Diseases of the heart valves. Edinburgh: Churchill Livingstone, 1989: chapter 5.

20 Inoue K. Percutaneous transvenous mitral commissurotomy using the Inoue balloon. Eur Heart f 1991;12 (suppl B):99108 .

21 Shaw TRD, Turnbull CM, Currie P, et al. A comparison of cylindrical and Inoue balloon techniques for mitral
valvotomy in patients in the United Kingdom. Br Heart $\mathcal{F}$ 1994:72:486-91.

22 Roth RB, Block PC, Palacios F. Prediction of increased mitral regurgitation after percutaneous mitral balloon valvotomy. Cathet Cardiovasc Diagn 1990;20:17-21.

23 Iung B, Cormier B, Farah B, et al. Percutaneous mitral commissurotomy in the elderly. Eur Heart f 1995;16:10929.

24 Nicolaou N, Kinsley RH. Mitral valve replacement in the elderly. $S A$ Med f 1984;65:598-600.

25 Nair CK, Biddle P, Kaneshige A, et al. Ten year experience with mitral valve replacement in the elderly. Am Heart $\mathcal{f}$ 1992;124:154-9.

26 Edmunds LH, Stephenson LW, Edie RN, et al. Open-heart surgery in octogenarians. N Engl f Med 1988;319:131-6.

27 Grossi EA, Galloway AC, Zakow PK, et al. Choice of mitral prossi EA, Galloway AC, Zakow PK, et al. Choice of mitral
prosthe elderly. An analysis of actual outcome. Circulation 1998;98(suppl II):116-19. 
28 Fatkin D, Roy P, Morgan JJ, et al. Percutaneous balloon mitral valvotomy with the Inoue single balloon catheter: commissural morphology as a determinant of outcome. $\mathscr{F}$

29 Cannan CR, Nichimura RA, Reeder GS, et al. Echocardiographic assessment of commissural calcium - a simple predictor of outcome after percutaneous mitral balloon valvotomy. $\mathcal{F} \mathrm{Am}$ Coll Cardiol 1997;29:175-80.
30 Report of a Working Group of the Royal College of Physicians of London. Cardiological intervention in elderly patients. London: Royal College of Physicians, 1991.

31 Sutaria N, Shaw TRD, Prendergast B, et al. Effect of commissural fusion on outcome of balloon mitral valvotomy: a transoesophageal study. Heart 1998;76 (suppl 1):P37.

\section{IMAGES IN CARDIOLOGY}

\section{Exclusion of a pulmonary artery aneurysm using a covered stent}
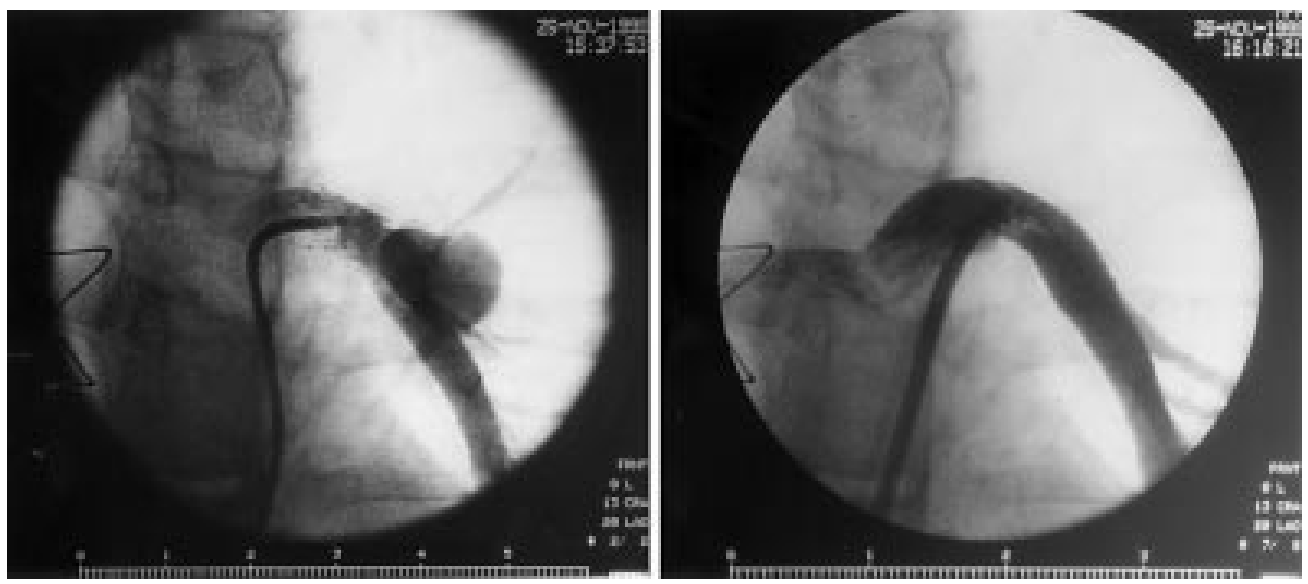

A 14 year old boy with multiple branch pulmonary arterial stenoses developed complete occlusion of the left pulmonary artery despite previous surgery. Intraoperative radiofrequency assisted stent angioplasty resulted in successful revascularisation of the left lung but angiography several months later showed a large pear shaped false aneurysm of the left pulmonary artery, measuring $20 \times 15 \mathrm{~mm}$ (left). Owing to distal pulmonary arterial stenoses, the systolic pressure in the aneurysm was more than half systemic with the potential risk of aneurysmal rupture. Catheter intervention was performed to exclude the aneurysm from the pulmonary circulation and a $17 \mathrm{~mm}$ long covered Jostent peripheral stent graft (JoMed International AB, Helsingborg, Sweden) was successfully deployed across the neck of the aneurysm. Angiography following deployment showed complete exclusion of the aneurysm without loss of calibre to the left pulmonary artery (right), but two apical branches to the left lower lobe were also occluded by the covered stent. After catheterisation, the patient had transient haemoptysis and chest radiography changes consistent with infarction of left lower lobe segments. Lung function and gas exchange were not compromised and he was discharged home two days after the procedure on aspirin $75 \mathrm{mg}$ once daily.

Seven months after the procedure the patient was well with resolution of chest radiography changes. Large aneurysms of the pulmonary artery are rare but we have demonstrated that they can be successfully treated by a covered stent, thus avoiding surgery, which can be hazardous due to the difficulty in achieving haemostasis deep within the lung parenchyma.

N WILSON

K MCLEOD D HALLWORTH 